\title{
Comparison of serum levels of vitamin $D$ and vitamin D-binding protein in normal, osteopenic and osteoporotic postmenopausal women
}

\author{
Rafat Murad', Tabassum Mahboob², \\ Rehana Rehman ${ }^{3}$, Rozeena Baig ${ }^{4}$
}

\section{ABSTRACT}

Objective: To compare the serum levels of vitamin D, vitamin D binding protein (VDBP) calcium and phosphate in normal, osteopenic and osteoporotic postmenopausal women categorized on the basis of bone mineral density (BMD) scores.

Methods: A cross sectional study carried out from May 2017 to August 2018. BMD measured by Dual energy $X$-ray Absorptiometry categorized women (aged 20-70 years) into normal $(n=37)(T$ score $\geq-1.0)$ osteopenic $(n=25)(-2.5<$ T score, $<-1)$ and osteoporotic $(n=26)(T$ score $<-2.5)$ according to WHO classification. Serum concentrations of vitamin D, VDBP, calcium, phosphate analyzed by enzyme linked immunosorbent assay were compared by Analysis of Variance

Results: In normal females higher levels of vitamin D and VDBP were observed [15.82 (8 - 69.18), 469.9 (269.57 - 875.55)] vs. osteopenic [(7.45 (4.66 - 15.1), 296.05 (232.58 - 420.23)] and osteoporotic women [(7.25 (3.97 - 17.49), 272.94 (202.23 - 351.24)]; [median interquartile range]; $p$ value $<0.0001$.

Conclusion: Vitamin D and VDBP are linked with bone health and estimation of VDBP appears to be a valuable tool for the assessment of increased bone loss and possible risks of bone fractures especially in postmenopausal women.

KEYWORDS: Vitamin D, Vitamin D-binding protein, Bone mineral density, Post menopausal females.

doi: https://doi.org/10.12669/pjms.35.2.714

How to cite this:

Murad R, Mahboob T, Rehman R, Baig R. Comparison of serum levels of vitamin D and vitamin D-binding protein in normal, osteopenic and osteoporotic postmenopausal women. Pak J Med Sci. 2019;35(2):543-548.

doi: https://doi.org/10.12669/pjms.35.2.714

This is an Open Access article distributed under the terms of the Creative Commons Attribution License (http://creativecommons.org/licenses/by/3.0), which permits unrestricted use, distribution, and reproduction in any medium, provided the original work is properly cited.

1. Prof. Rafat Murad, MBBS, M.Phil. Department of Biochemistry,

BMSI, JPMC, Karachi, Pakistan.

2. Prof. Tabassum Mahboob, PhD.

Department of Biochemistry,

University of Karachi, Karachi Pakistan.

3. Dr. Rehana Rehman, MBBS, M.Phil., PhD.

Associate Professor,

4. Rozeena Baig, MSc.

3, 4: Department of Biological \& Biomedical Sciences, Aga Khan University, Karachi, Pakistan.

\section{Correspondence:}

Dr. Rehana Rehman,

Department of Biological \& Biomedical Sciences, Aga Khan University, Karachi, Pakistan.

Email: drrehana7@gmail.com

* Received for Publication:

* $1^{\text {st }}$ Revision Received:

* $2^{\text {nd }}$ Revision Received:

* Final Revision Accepted:
October 31, 2018

February 18, 2019

March 6, 2019

March 8, 2019

\section{INTRODUCTION}

Vitamin D deficiency is common in general population. ${ }^{1}$ About one billion people suffer from vitamin $\mathrm{D}$ deficiency around the globe. ${ }^{2}$ Adequate vitamin $\mathrm{D}$ is essential for maintaining skeletal growth owing to its central role in calcium and phosphate metabolism. ${ }^{3}$ Vitamin D ensures the mineralization of the organic matrix of bone, and also mediates the release of calcium and phosphate from bone to achieve mineral homeostasis. ${ }^{4}$ Calcium and phosphate not only helps in achieving peak bone before the onset of menopause and age related decline in bone formation but also provide protection against bone loss and fractures. ${ }^{5}$

Low levels of vitamin $\mathrm{D}$ have been shown to have adverse effects on calcium metabolism, osteoblastic 
activity, matrix ossification, bone mineral density (BMD). Deficiency of vitamin D leads to the development of osteomalacia (incomplete mineralization of osteoid) in adults and rickets in children. Chronic insufficiency of vitamin D leads to secondary hyperparathyroidism with increased bone turnover and decreased BMD. The progressive bone loss exacerbates both osteopenia and osteoporosis and increased risk of fragility fractures especially in elderly individuals. ${ }^{6}$

Concentration of vitamin D within the body is affected by various factors including age, body weight, ethnicity, genetic polymorphisms and vitamin D-binding protein (VDBP), the primary vitamin $\mathrm{D}$ carrier protein. ${ }^{7}$

Majority of vitamin D in serum is bound to VDBP (80-90\%), and also bound to albumin and chylomicrons $(10-15 \%)$ at lower levels and affinity, very small fraction is free $(<0.1 \%)$ and is biologically active. Vitamin D bound to VDBP, facilitates the access of vitamin $\mathrm{D}$ to various tissues and cells and regulates the total amount of vitamin $\mathrm{D}$ available for the organism. It protects vitamin D metabolites from hydroxylase-mediated catabolism and therefore act as vitamin D reservoir. ${ }^{8}$ The hepatic synthesis of VDBP is stimulated by estrogen as seen in various studies that showed increase in serum concentration of VDBP in pregnant females and in women taking exogenous estrogen. ${ }^{9}$

Menopause either involutional or estrogen related is associated with increased bone turnover and risk of osteoporotic fracture owing to multiple factors including low levels of total circulating vitamin $\mathrm{D}$ and VDBP. ${ }^{10}$ The current study was designed to compare the serum levels of vitamin $\mathrm{D}$, VDBP, calcium, phosphate along with biophysical parameters in normal, postmenopausal osteopenic and osteoporotic women and also to examine the relationship between vitamin $\mathrm{D}, \mathrm{VD}, \mathrm{BP}$ and BMD in all three groups.

\section{METHODS}

This cross-sectional study comprised of 88 healthy women (aged 20-70 years). Study was conducted in the Department of Biological \& Biomedical Sciences Aga Khan University from May 2017 - August 2018 after approval from Ethical Committee of Aga Khan University (4146-BBS-ERC-16). Combined prevalence of osteoporosis and osteopenia is $82 \% .{ }^{11} \mathrm{We}$ calculated 57 sample size for osteopenic and osteoporotic group using infinite formula for sample size calculation for osteoporosis and osteopenic groups with $95 \%$ confidence level (1.96), prevalence $82 \%$ and margin of error $10 \%$ in the following formula; $\mathrm{n}=\left(\mathrm{Z}^{\wedge} 2 \mathrm{pq}\right) / \mathrm{e}^{\wedge} 2$

$\mathrm{n}=\left((1.96)^{\wedge} 2(0.82)(0.18)\right) /(0.1)^{\wedge} 2$

$\mathrm{n}=57$

We collected data of 57 subjects, but due to drop out of 6 subjects, we compared 51 postmenopausal women with minimum significant normal (37) subjects

Where: $\mathrm{z}=$ standard normal deviation set at $95 \%$ confidence level

$\mathrm{p}=$ percentage picking a choice or response

$\mathrm{c}=$ confidence interval

The subjects were recruited from the community, motivated to come to AKU where their free DEXA scans were done and blood samples were acquired after taking written informed consent from each participant. Weight was recorded digitally to the nearest $0.1 \mathrm{~kg}$ while height was recorded to the nearest $0.1 \mathrm{~cm}$ using seca 217 stadiometer. Body mass index (BMI) was calculated as the ratio of weight $(\mathrm{kg})$ and height $\left(\mathrm{m}^{2}\right)$.

Subjects were recruited by organizing health camps in different districts of Karachi through convenient sampling (Fig.1). Participants with history of premature menopause, vertebral fractures or suffering from systemic illness like hyperthyroidism, hyperparathyroidism, renal failure or taking any medications known to affect bone metabolism like bisphosphonates, calcium, vitamin D supplements, calcitonin, hormone replacement therapy and anabolic steroids were excluded from the study. Women were further categorized on the basis of BMD measurements according to WHO classification into, normal ( $\mathrm{T}$ score $\geq-1.0)(\mathrm{n}=37)$ osteopenic $(n=25)(-2.5<T$ score, $<-1)$ and osteoporotic $(n=26)$ (T score <-2.5). ${ }^{12}$ BMD in $(\mathrm{gm} / \mathrm{cm} 2)$ was measured by DEXA scan by Hologic discovery A (S/N 80855). Sites of measurement were hip, femoral neck and spine (L1-L4).

Serum vitamin D, VDBP, calcium and Phosphate were measured by solid phase enzyme amplified sensitivity immunoassay method (commercial kit DIA source immunoassay, Belgium) kitCat $\neq 95503$ for vitamin $D$, kit Cat $\neq 97145$ for VDBP). Calcium and phosphate were measured by kit Cat $\neq$ SP 1001061, and kit Cat $\neq$ SP1001150 respectively. Cut off values for deficient, insufficient and sufficient vitamin D levels were taken to be $<20 \mathrm{ng} / \mathrm{ml}, 20$ $30 \mathrm{ng} / \mathrm{ml}$ and $>30 \mathrm{ng} / \mathrm{ml}$ respectively. ${ }^{13}$ Statistical analyses were done using Statistical Package for Social Sciences SPSS (version 21). Baseline characteristics of the participants were analyzed by descriptive statistics (mean \pm SD). Statistical 


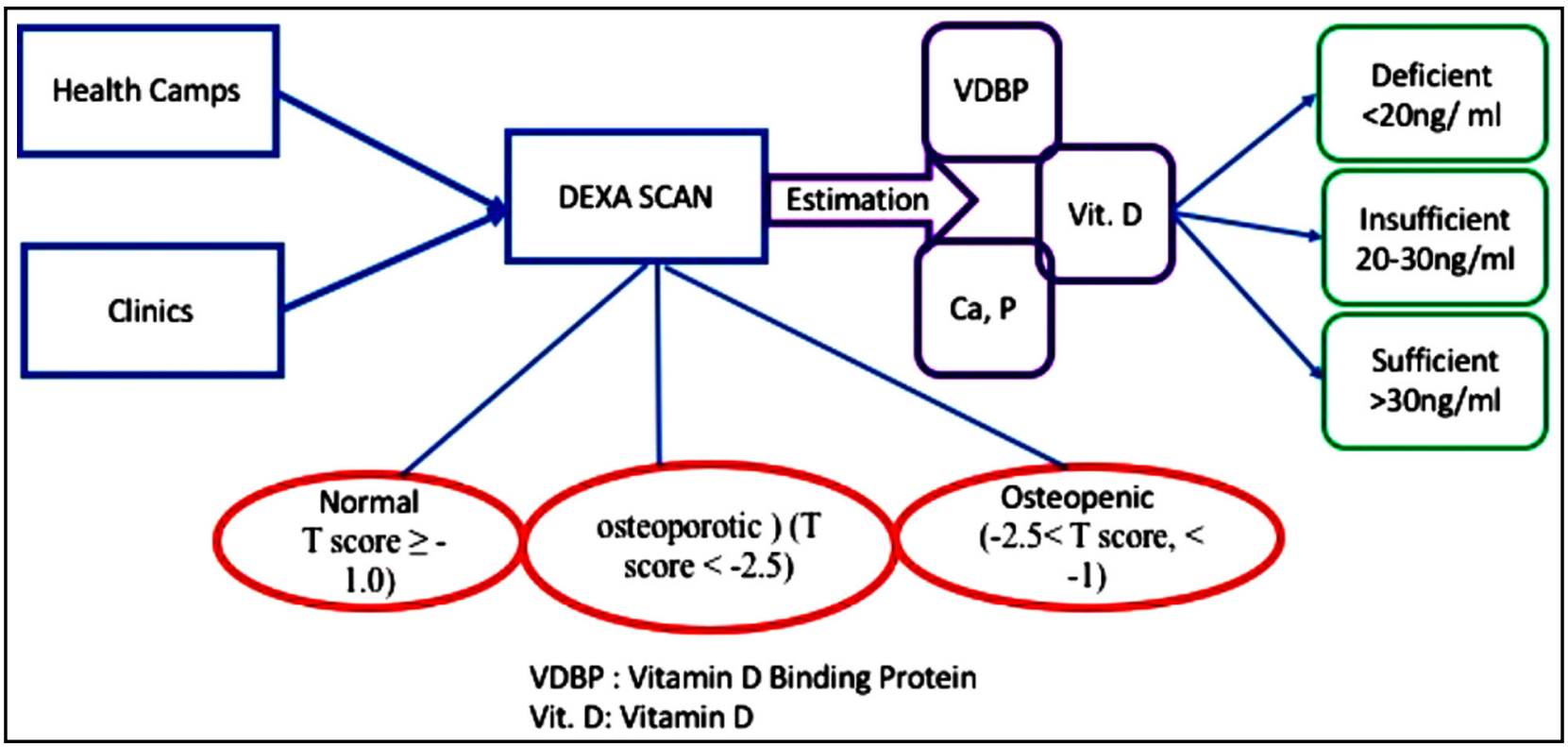

Fig.1: Patient selection flow chart.

comparison was performed using ANOVA, post hoc Tukey HSD test was then applied. All p-values $<0.05$ were taken as significant.

\section{RESULTS}

Total 88 healthy women were included in this study, out of which 37 were normal, 25 were osteopenic and 26 were osteoporotic women as per estimation of BMD. In normal group $(n=37)$ premenopausal women were $(n=30,11.1 \%)$, and postmenopausal women were $(n=7,2.5 \%)$, whereas osteopenic $(n=25)$ and osteoporotic group $(n=26)$ comprised only of postmenopausal women.

Table-I: Comparison of baseline characteristics of the participants.

\begin{tabular}{lcccc}
\hline & Normal (37) & Osteopenic (25) & Osteoporotic (26) & P value \\
\hline Age (years) & $36.43 \pm 13.71$ & $52.48 \pm 10.324$ & $58.577 \pm 5.021^{* * \wedge \wedge}$ & $<0.001$ \\
Height (centimeters) & $157.21 \pm 5.678$ & $155.256 \pm 4.792$ & $154 \pm 5.546$ & 0.06 \\
Weight & $62.8 \pm 12.886$ & $67.12 \pm 11.641$ & $60.904 \pm 9.846$ & 0.15 \\
BMI kg/m ${ }^{2}$ & $25.319 \pm 5.463$ & $28.132 \pm 5.073$ & $26.262 \pm 4.943$ & 0.11 \\
Duration of Menopause (years) & & $8.286 \pm 3.717$ & $7.885 \pm 3.953$ & 0.16 \\
Vitamin D (ng/ml) & $15.82(8-69.18)$ & $7.45(4.66-15.1)$ & $7.25(3.97-17.49) \wedge$ & 0.06 \\
Median (Interquartile Range) & & $296.05(232.58-$ & $272.94\left(202.23-351.24^{* \wedge}\right.$ & 0.01 \\
VDBP (ng/ml) & $469.9(269.57-875.55)$ & $420.23)$ & $7.86 \pm 1.559$ & 0.35 \\
Median (Interquartile Range) & $7.643 \pm 1.37$ & $7.3 \pm 1.1216$ & $4.457 \pm 1.11$ & 0.80 \\
Calcium mg/dl & $4.385 \pm 1.084$ & $4.572 \pm 1.033$ & $-1.95 \pm 0.62$ & $<0.001$ \\
Phosphate mg/dl & $-0.543 \pm 0.803$ & $-0.728 \pm 0.648$ & $-2.95 \pm 1.047$ & $<0.001$ \\
Dexa Hip score & $0.797 \pm 0.65$ & $-1.556 \pm 1.023$ & $-2.527 \pm 0.556$ & $<0.001$ \\
Dexa score spine & $0.927 \pm 0.705$ & $-1.476 \pm 0.63$ & & \\
Dexa Hip femoral neck & & & \\
\hline
\end{tabular}

Values are expressed in mean \pm Standard deviation or Median (Interquartile range)

Analysis of variance was used to compare means between groups.

* $p$ value $<0.05$ is significant in osteoporotic group as compared to osteopenic

${ }^{* *} \mathrm{p}$ value $<0.001$ is significant osteoporotic group as compared to osteopenic

$\wedge \mathrm{p}$ value $<0.05$ is significant in osteoporotic group as compared to normal

$\wedge \wedge p$ value $<0.001$ is significant in osteoporotic group as compared to normal. 
The characteristics of study participants are shown in Table-I. Serum levels of vitamin D and VDBP were significantly different across groups and were on higher side in normal compared to osteopenic and osteoporotic group ( $\mathrm{p}$-value < $0.0001)$

The Fig.2 describes the distribution of normal, osteopenic and osteoporotic groups on the basis of cut off values of vitamin D (deficiency $<20 \mathrm{ng} / \mathrm{ml}$, insufficiency $20-30 \mathrm{ng} / \mathrm{ml}$, sufficiency $>30 \mathrm{ng} / \mathrm{ml}^{13}$ It shows that in normal group $(n=37)$ the number of females deficient, insufficient and sufficient for vitamin D levels were $35 \%, 22 \%$ and $43 \%$ respectively. Vitamin D levels in normal women differed significantly from osteopenic group 56\% deficient, $28 \%$ insufficient and $16 \%$ sufficient. In osteoporotic group $62 \%$ females were deficient, $23 \%$ were insufficient and $15 \%$ had sufficient Vitamin D levels respectively ( $\mathrm{p}$ value $<0.0001$ ).

Fig.3 describes the representation of median values of VDBP in all study groups. In normal group, serum VDBP levels were higher $(594.583 \pm 397.601 \mathrm{ng} /$ $\mathrm{ml})$ compared to osteopenic $(348.524 \pm 183.501 \mathrm{ng} /$ $\mathrm{ml})$ and osteoporotic group $(278.934 \pm 109.582 \mathrm{ng} /$ ml) ( $p$ value $<0.0001)$.

\section{DISCUSSION}

Hypovitaminosis D is common worldwide and affects children and elderly people predominantly postmenopausal women. ${ }^{14,15}$ Our study shows that serum levels of vitamin D and VDBP were lower in postmenopausal osteopenic and osteoporotic women compared to the normal group. Similar findings can be compared by another study which explained lower levels of estrogen as a

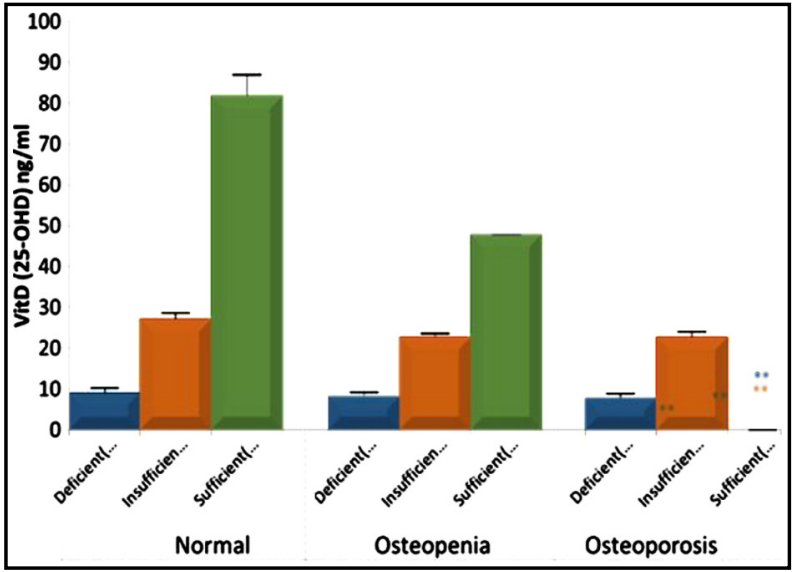

Fig.2: Vitamin D levels in normal, osteopenic and osteoporotic females on the basis of cut off values deficient, insufficient and sufficient vitamin $D$ levels were taken to be<20ng/ $\mathrm{ml}, 20-30 \mathrm{ng} / \mathrm{ml}$ and $>30 \mathrm{ng} / \mathrm{ml}$. contributing factor for low vitamin D concentration in postmenopausal women. ${ }^{16}$ Present study also showed higher mean age in osteoporotic group compared to the normal group which also suggests an age-related phenomenon responsible for decreased vitamin $\mathrm{D}$ levels in these women. Impaired function of the enzyme 1 a hydroxylase required for the formation of active vitamin $\mathrm{D}(1,25$ dihydroxycholicalciferol) and increased metabolic clearance of vitamin D metabolites is responsible for a decline in vitamin $\mathrm{D}$ levels seen in elderly postmenopausal osteoporotic women. ${ }^{17}$ Results of this study also showed that BMD measured at hip, spine and femoral neck was also significantly lower in postmenopausal osteopenic and osteoporotic women having lower serum vitamin $\mathrm{D}$ levels compared to the normal group. Similar finding are reported by Nakamura et al showing decline in BMD at femoral neck in subjects having low vitamin D levels compared to those having adequate levels of vitamin D. ${ }^{18}$

Serum calcium and phosphate were low in all three study groups, as shown in our results; however no significant difference was seen among three groups. This may be related to either low intake or impaired absorption of minerals seen in vitamin D deficiency or inadequacy. ${ }^{19}$

Among postmenopausal osteoporotic women the prevalence of vitamin D deficiency was $62 \%$ using a cut off value $<20 \mathrm{ng} / \mathrm{ml}$ and insufficiency was $23 \%$, using a cut-off of $20-30 \mathrm{ng} / \mathrm{ml}$. Previous literature

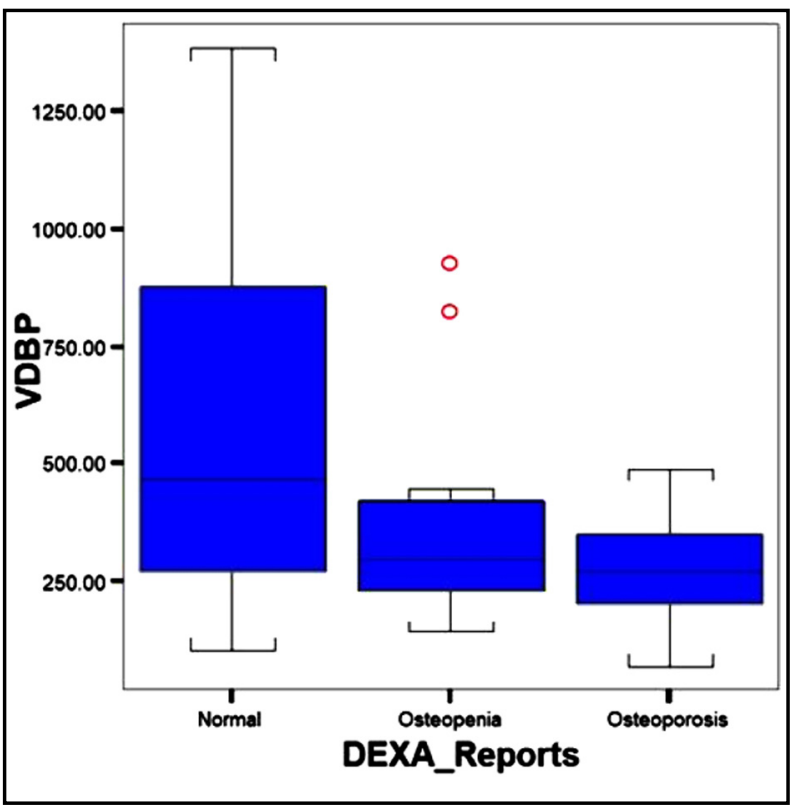

Fig.3: Comparison of Vitamin D-binding proteins in the study groups. 
has reported increased serum levels of parathyroid hormone in subjects having low serum vitamin D levels $<20 \mathrm{ng} / \mathrm{ml}$ causing decrease in calcium absorption and serum calcium concentration, which is maintained as the expense of increased parathyroid secretion, referred to as secondary hyperparathyroidism..$^{20}$ Several observational studies have reported the association of serum vitamin D levels with osteoporotic fractures. A cohort study conducted by Tanaka et al comprising of 1470 postmenopausal women revealed that those with serum vitamin D levels $<25 \mathrm{ng} / \mathrm{ml}$ showed a significant higher risk of long bone fracture. ${ }^{21}$ Another study comprising of 1262 postmenopausal women have reported higher incidence of 5 year total fracture risk among postmenopausal women having basal serum vitamin D levels $<10 \mathrm{ng} / \mathrm{ml}$ followed by those whose vitamin $\mathrm{D}$ levels were between $10-20 \mathrm{ng} / \mathrm{ml}$ and $20-30 \mathrm{ng} / \mathrm{ml}$ and was lowest in those having $>30 \mathrm{ng} / \mathrm{ml}^{22}$

Various factors are responsible for maintaining vitamin $\mathrm{D}$ status including VDBP which is responsible for maintaining the availability and regulation of serum vitamin $\mathrm{D}$ levels. This study results have shown that VDBP concentration was lower in osteoporotic women compared to normal group of women. Others have also shown decreased levels of VDBP in females than in males, which could be due to differences in estrogen levels. ${ }^{23}$ Increased serum VDBP levels have also been reported in women receiving hormone replacement therapy, oral contraceptives and in pregnancy. ${ }^{24}$ Similarly concomitant decreased concentration of VDBP and vitamin D in postmenopausal osteoporotic women as reported in our study, might be due to physiological adaptation to maintain free vitamin D levels or due to a compensatory mechanism of reduced hepatic synthesis of VDBP as result of decreased vitamin $\mathrm{D}$ in postmenopausal osteoporotic women. ${ }^{25}$

Our study also highlighted increased serum levels of VDBP in normal premenopausal women compared to postmenopausal osteoporotic women. This can be due to the deficiency of estrogen hormone in postmenopausal women, which is required in higher concentration to raise serum levels of VDBP as identified in previous estrogen administration studies and during pregnancy. ${ }^{26}$

This study results have identified the role of vitamin D and VDBP for evaluating the risk of osteoporosis and osteoporotic related fractures in postmenopausal women, but due to limited number of patients, we could not draw conclusions from the findings. Further studies with large sample size are needed to assess the role of vitamin D and VDBP in the prediction of loss of BMD and risk of fragility fractures especially in postmenopausal osteoporotic women. We have not related our results with exposure to sun, latitude, season, time of day, and atmospheric components as all subjects were permanent residents of Karachi. Also initial screening at camps ruled out subjects positive for certain other factors like obesity, chronic illnesses and smoking etc.

\section{CONCLUSION}

Serum levels of vitamin D and VDBP were lower in osteopenic and osteoporotic post-menopausal women as compared to the normal females who reflected normal bone architecture as evidenced by normal BMD. Vitamin D and VDBP are thus important for incremental increase in BMD, furthermore recommend that VDBP may be used as a valuable tool to identify the risk of osteoporotic fractures associated with decline in BMD especially in postmenopausal women.

Declaration of Interest: The authors declare no conflict of interest.

Grant Support and Financial Disclosures: The study was supported by a grant from Higher Education Commission (No.5215/Sindh/NRPU/ $\mathrm{R} \& \mathrm{D} / \mathrm{HEC} / 2016$ ) and is in accordance to the policy of the funding organization on research objectivity. We are extremely thankful to the Department of Biochemistry BMSI, JPMC Karachi and especially Dr. Rafat Murad for approaching (pre and postmenopausal females), inviting them to come for enrollment in the study, providing them slots for DEXA scan and facilitating their work up at AKU. Our special thanks to Dr. Aisha Sheikh, Consultant Endocrinologist at Aga Khan University Hospital.

\section{REFERENCES}

1. Holick MF. The vitamin D deficiency pandemic: Approaches for diagnosis, prevention and treatment. Rev Endocr Metab Disord. 2017;18(2):153-165. doi: 10.1007/s11154-017-9424-1.

2. Hilger J, Friedel A, Herr R, Rausch T, Roos F, Wahl DA, et al. A systematic review of vitamin D status in populations worldwide. Br J Nutr. 2014;111(1):23-45. doi: 10.1017/ S0007114513001840.

3. Wang H, Chen W, Li D, Yin X, Xang X, Olsen N et al. Vitamin D and Chronic Diseases. Aging Dis. 2017;8(3):346-353. doi: 10.14336/AD.2016.1021.

4. Cosman F, de Beur SJ, LeBoff MS, Lewiecki EM, Tanner B, et al. Clinician's Guide to Prevention and Treatment of Osteoporosis 2014. Osteoporos Int. 2014;25(10):2359-2381. doi: 10.1007/s00198-014-2794-2. 
5. Bonjour J, Theintz, Bertrand B, Slosman D, Rizzoli R. Critical years and stages of puberty for spinal and femoral bone mass accumulation during adolescence. J. Clin Endocrinol Metab. 1991;73:555-563

6. Thacher TD, Clarke BL. Vitamin D insufficiency. Mayo Clin Proc. 2011;86(1):50-60 doi: 10.4065/mcp.2010.0567.

7. Meller UK, Streym L, Heickendorff L, Mosekilde L, Rejnmark L. Effects of 25(OH)D concentration on chances of pregnancy and pregnancy outcome: a cohort study in healthy Danish women. Eur J Clin Nutr. 2012;66:862-868

8. Jones KS, Assar S, Harnpanich D, Bouillon R, Lambrechts D, et al. 25(OH)D2 half-life is shorter than $25(\mathrm{OH}) \mathrm{D} 3$ half-life and is influenced by DBP concentration and genotype. J Clin Endocrinol Metab.2014;99:3373-3381. doi: 10.1210/jc.2014-1714.

9. Pirani T, Chen J, Viera A. Effects of estradiol on the endocyte transport of vitamin D carrier protein in hepatocytes. Biochem Biophys Acta. 2013;1830:3421-3426.

10. Yousefzadeh P, Shapses SA, Wang X. Vitamin D Binding Protein Impact on 25-Hydroxyvitamin D Levels under Different Physiologic and Pathologic Conditions. Int. J. Endocrinol. 2014:981581. doi: 10.1155/2014/981581.

11. Ejaz S, Mahmood A, Qureshi MA, Ali M. Prevalence of osteoporosis and osteopenia among Pakistani pre and post menopausal women. J Dent Med Sci. 2012;2(6):12-17.

12. Choi ST, Jung JY, Kim HA, Kim SS, Kim SH, et al. Prevalence and Fracture Risk of Osteoporosis in Patients with Rheumatoid Arthritis: A Multicenter Comparative Study of the FRAX and WHO criteria. J Clin Med. 2018;7(12):507. doi: $10.3390 / \mathrm{jcm} 7120507$

13. Holick MF, Binkly NC, Bischoff-Ferrari HA, Gordon CM, Hanley DA, Heaney RP, et al. Evaluation, treatment, and prevention of vitamin D deficiency: an endocrine society clinical practice guideline. J Clin Endocrinol Metab. 2011;96:1911e30.

14. American Geriatrics Society Workgroup on Vitamin D Supplementation for Older Adults. Recommendations abstracted from the American Geriatrics Society Consensus Statement on vitamin D for Prevention of Falls and Their Consequences. J Am Geriatr Soc. 2014;62(1):147-152. doi: 10.1111/jgs.12631.

15. Looker AC, Johnson CL, Lacher DA, Pfeiffer CM, Schleicher RL, Sempos CT. Vitamin D status: United States, 2001-2006. NCHS Data Brief. 2011;59:1-8.

16. Pop LC, Shapses SA, Chang B, Sun W, Wang X. Vitamin D-Binding protein in healthy pre and postmenopausal women: Relationship with estradiol concentrations. Endocr Pract. 2015;21(8):936-942. doi: 10.4158/EP15623.OR.

17. Kroll MH, Bi C, Garber CC, Kaufman HW, Liu D, CastonBalderrama A, et al. Temporal Relationship between vitamin D Status and Parathyroid Hormone in the United States. 2015;10(3):e0118108. doi: 10.1371/Journal.pone.0118108.

18. Nakamura $K$, Tsugawa N, Saito T, Ishikawa $M$, Tsuchiya $\mathrm{Y}$, Hyodo K, et al. Vitamin D status, bone mass and bone metabolism in home - dwelling postmenopausal Jappanese women: Yokogoshi Study. Bone. 2008;42(2):271-277.
19. Wintermeyer E, Ihle C, Ehnert S, Stockle U, Ochs G, Zawart $\mathrm{PD}$, et al. Crucial role of vitamin D in the Musculoskeletal system. Nutrients 2016;8(6): doi: 10.3390/nu8060319.

20. Valcour A, Blocki F, Hawkins DM, Rao SD. Effect of age and serum $25(\mathrm{OH})$ Vitamin D on serum parathyroid hormone levels. J Clin Endocrinol Metab 2012:97(11):3989-3995.

21. Tanaka S, Kuroda T, Yamazaki Y, Shiraki Y, Yoshimura N, et al. Serum 25 -hydroxyvitamin $\mathrm{D}$ below $25 \mathrm{ng} / \mathrm{mL}$ is a risk factor for long bone fracture comparable to bone mineral density in Japanese postmenopausal women. J Bone Miner Metab. 2014;32(5):514-523. doi: 10.1007/s00774-013 -0520-3.

22. Tamaki J, Iki M, Sato Y, Kajita E, Nishino H, Akiba T, et al. Total 25-hydroxyvitamin D levels predict fracture risk: results from the 15-year follow-up of the Japanese Population-based Osteoporosis (JPOS) cohort study. Osteoporosis Int. 2017;28(6):1903-1913. doi: 10.1007/s00198017-3967-6.

23. Blanton D, Han Z, Bierschenk L, Linga-Reddy MV, Wang H, Clare-Salzler M, et al. Reduced serum vitamin D- binding protein level are associated with type 1 diabetes. Diabetes. 2011;60(10):2566-2570. doi: 10.2337/db11-0576.

24. Meller UK, Streym SV, Jensen LT. Increased plasma concentration of vitamin D metabolites and vitamin D binding protein in women using hormonal contraceptives: a cross sectional study. Nutrients. 2013;5;5(9):3470-3480. doi: 10.3390/nu5093470.

25. Ponda MB, McGee D, Breslow JL. Vitamin D binding protein levels do not influence the effect of vitamin D repletion on serum PTH and calcium: data from a randomized, controlled trial. J Clin Endocrinol Metab. 2014;99(7):24942499. doi: 10.1210/jc.2014-1181.

26. Powe CE, Evans MK, Wenger J, Zonderman AB, Berg AH, Nalls $M$, et al. Vitamin D- binding protein and vitamin $D$ status of black Americans and white Americans. N Engl J Med. 2013;369(21):1991-2000. doi: 10.1056/NEJMoa1306357.

\section{Authors' Contribution:}

RR: Conceived the idea.

RM and TM: Designed \& executed the study, did statistical analysis and took part in the writing of the manuscript.

RB: Collected the data, helped in statistical analysis and manuscript writing.

All authors reviewed for final approval of the manuscript. 